(C) [2009] IEEE. Reprinted, with permission, from Xu, Wei; Zhu, Jianguo; Guo, Youguang; Wang, Shuhong; Wang, Yi; Shi, Zhanghai. 2009, Survey on Electrical Machines in Electrical Vehicles', Proceedings of IEEE International Conference on Applied Superconductivity and Electromagnetic Devices, pp. 167-170. This material is posted here with permission of the IEEE. Such permission of the IEEE does not in any way imply IEEE endorsement of any of the University of Technology, Sydney's products or services. Internal or personal use of this material is permitted. However, permission to reprint/republish this material for advertising or promotional purposes or for creating new collective works for resale or redistribution must be obtained from the IEEE by writing to pubs-permissions@ieee.org. By choosing to view this document, you agree to all provisions of the copyright laws protecting it. 


\section{Survey on Electrical Machines in Electrical Vehicles}

\author{
Wei Xu, Jianguo Zhu, Youguang Guo, \\ Shuhong Wang,Yi Wang \\ Faculty of Electrical Engineering and Information \\ Technology, University of Technology, Sydney \\ Sydney, Australia \\ wxu@eng.uts.edu.au,joe@eng.uts.edu.au
}

\author{
Zhanghai Shi \\ Department of Electrical Engineering, Hong Kong \\ Polytechnic University \\ Hong Kong, China \\ ee.zhhshi@polyu.edu.hk
}

\begin{abstract}
With great concerns on clean environment, there is a fast growing interest in electrical vehicles (EVs). As one of the key technologies, the motor drive has been developed quickly. In this paper, the characteristics of four traditional machines are first reviewed and evaluated, which include the direct current machine (DCM), induction machine (IM), switched reluctance machine (SRM) and permanent magnet brushless machine (PMBM). Then, the topologies and performances of four special machines are discussed, including the transverse flux machine (TFM), axial flux machine (AFM), doubly salient permanent magnet machine (DMPM) and dual mechanical port electrical machine (DMPEM). Finally, future research trends of electrical machines in EVs are described.
\end{abstract}

Keywords-electrical vehicles; electrical machines; motor drive; machine design; traditional machines; special machines

\section{INTRODUCTION}

Due to the increasing demand for higher power and less fuel consumption in cars, the electrical vehicle (EV) technologies have experienced an accelerated pace. In the drive system, the technology of electrical machines is the crucial factor that decides the system efficiency and performance.

The requirements on the basic characteristics of an electrical machine in EV drive system are indicated below [15]: (1) High power density and torque density; (2) Wide speed range with constant power operation around 3-4 times the base speed; (3) High starting torque, great hill climbing ability, and high power in speed cruising; (4) High efficiency over wide speed and torque ranges; (5) High reliability and robustness appropriate to environment; (6) Intermittent overload ability and acceptable cost; (7) Low acoustic noise and low torque ripple; and (8) Good voltage regulation over wide speed.

Ideal torque \& power-speed curves for a traction machine are shown in Fig. 1. In the constant torque region $I$, the maximum torque capability is decided by the current rating of the inverter. In the constant power region II, flux weakening is employed due to the limitation of the inverter voltage and current. In region III, the torque and power decrease due to the increase of the back-electromotive force [2,5].

According to the requirement of electrical machines in EVs, researchers have studied lots of structures. This paper is organized as follows. In section II, the general introduction of four traditional electrical machines is presented. In section III, evaluation and comparison are made on the traditional machine efficiency, power density, reliability, etc. In section IV, analysis and discussion of four special electrical machines are provided, whose performances have been improved by using new structures, materials and/or control schemes. In section V, the next research orientation on electrical machines is discussed. Conclusions are made in section VI.

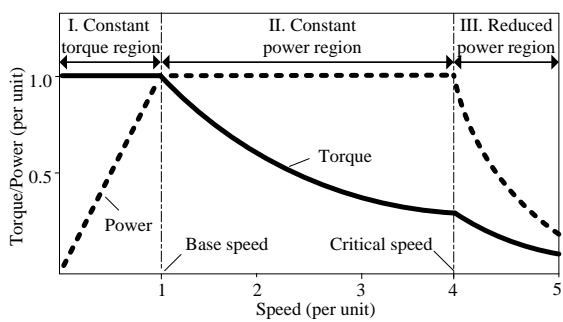

Figure 1. Ideal torque \& power-speed curves.

\section{StRUCTURES OF TRADITIONAL ELECTRICAL MACHINES IN EVS}

Among different types of electric drives, there are mainly two kinds of machines: the brushed and the brushless ones [1, 4]. They include four major types, namely DC machine (DCM), induction machine (IM), switched reluctance machine (SRM), and permanent magnet brushless machine (PMBM), as illustrated in Fig. 2.

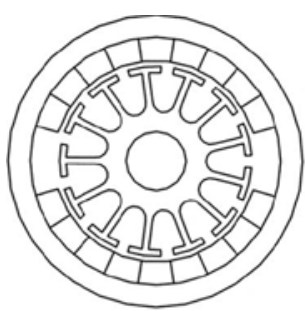

(a)

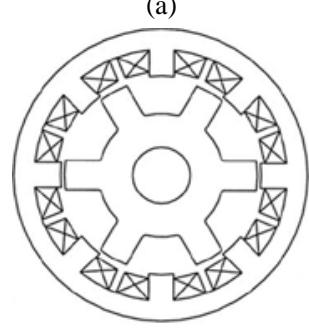

(c)

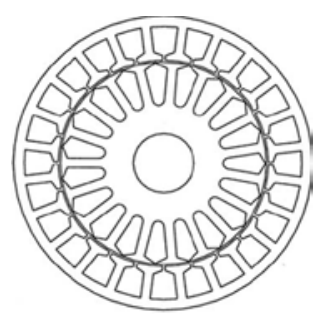

(b)

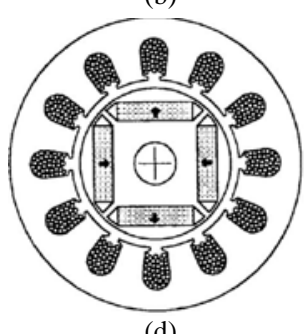

(d)
Figure 2. Structures of four traditional electrical machines: (a) DCM, (b) IM, (c) SRM, and (d) PMBM 


\section{A. Direct Current Machine (DCM)}

DC machines include wound-field DC machine and permanent magnet DC machine shown in Fig. 2(a). Practically, the performance of DC motors can be described by the armature voltage, back electromotive force (EMF), and field flux. There are typically four types of wound-field DC motors, depending on the mutual interconnection between the field and armature windings. They are separately excited, shunt excited, series excited, and compound excited.

The advantages of a DC machine include: (1) Technological maturity and control simplicity; (2) Good speed regulation, and frequent starting, braking and reversing.

The main disadvantages are: (1) It needs commutators and brushes to feed current into the armature, hence it is less reliable and unsuitable for maintenance-free operation and high speed; (2) Winding excited DC motors have low specific power density.

\section{B. Induction Machine (IM)}

There are two types of induction motors, namely, woundrotor and squirrel cage motors. The wound-rotor IMs are less attractive than their squirrel-cage counterparts for their higher cost, more maintenance, and lack of sturdiness shown in Fig.2 (b). The most common types of induction motor rotors are the squirrel cage in which aluminum bars are cast into slots in the outer periphery of the rotor [5].

The main advantages of IM include: (1) Robust structure and relatively low cost; (2) Good dynamic performance which can be achieved by for example vector control and direct torque control; (3) Light weight, small volume and high efficiency.

The disadvantages include: (1) The constant power range can only extend to 2-3 times the base speed. But in EV machines, it requires an expansion of 4-5 times above the base one. Hence, the design of IM is more complicated to satisfy the EV demand; (2) The control schemes are a little difficult due to the variable equivalent parameters.

\section{Switched Reluctance Machine (SRM)}

SRM is operated in the discontinuous current mode shown in Fig.2(c). In Fig. 1, the constant torque region I, the phase currents of SRM are controlled by PWM to produce the desired output torque. The constant power area, region II, is up to 2-7 times the base speed, which is often achieved by phase advancing the excitation until overlap between successive phase currents occurs. In region III, the inverter supply voltage is limited, hence commutation advance is required. Both the turn-on and turn-off angles are gradually advanced with the speed increasing. Due to the influence of the back EMF and the winding inductance, further communication advance is limited and the phase current waveforms become continuous. The power capability in this condition can be obtained by employing two-phase overlapping excitation and continuous conduction [6].

The main advantages of SRM include: (1) The structure without magnets or windings on the rotor is simple and robust. Hence, it can be adopted in high-temperature environment and high-speed operation. (2) It is of low cost and inherent fault tolerance.

The main disadvantages are: (1) Smooth operation at low rotational speeds requires complex profiling of phase current waveforms and accurate rotor position. (2) The operation is based on the sequential excitation of opposite stator coils, hence the acoustic noise, vibration, and torque ripple tend to be comparatively high. (3) The magnetic circuit tends to be highly saturated.

In summary, SRMs have high-speed operating capability, relatively wide constant power capability, and the minimal effects of temperature variations offset, which have great potential application in vehicle propulsion systems.

\section{Permanent Magnet Brushless Machine (PMBM)}

PMBMs include sinusoidal and trapezoidal back-EMF machines. From the control schemes, they are divided into brushless DC (BLDC) and brushless AC (BLAC). Generally, a trapezoidal back-EMF waveform in BLDC or a sinusoidal back-EMF waveform in BLAC is needed so as to achieve high torque density and low torque pulsation [7].

BLDC has surface-mounted magnets on the rotor, and a concentrated fractional stator winding, which results in a low copper loss. In BLAC, various design methods are adopted to obtain a sinusoidal back-EMF waveform. The stator slots or rotor magnets may be skewed, and the permanent magnets could be appropriately shaped or magnetized. The interior permanent magnet (IPM) machine shown in Fig. 2(d), has larger leakage inductance than that of a surface PM machine [12].

The main advantages of PMBM are: (1) Light weight, small volume, and high power density as the magnetic field is excited by high-energy PMs. (2) High efficiency, high reliability, and good heat dissipation.

The main disadvantages include: (1) The range of constant power operation is comparatively narrow due to the difficultly in weakening the air gap flux. By using some new schemes, the speed range can reach three times the base velocity. However, the PM may suffer from demagnetization and possible fault. (2) Relatively high cost due to PM materials, especially in high power application.

\section{PERFORMANCE COMPARISON OF TRADITIONAL ELECTRICAL MACHINES IN EVS}

Different types of electrical machines in major EVs are shown in Table I. The evaluation of the EV motors is shown in Table II, where a point grading system is adopted [1, 3]. The grading system consists of six major characteristics and each of them is graded from 1 to 10 points, where 10 points means the best. It can be seen that IM drives and PM brushless motor drives are the main stream in today's EV electric propulsion.

In most cases, we care for a speed ratio $x$, which is defined as the ratio of the maximum speed to the base speed. Each type of motor has its limited maximum speed ratio. The permanent magnet motor has a small $x(<=2)$, because it is difficult to employ the field weakening control. The switched reluctance 
motor has the biggest ratio $(>=6)$, while an induction motor may achieve a ratio of 4 .

TABLE I. APPLiCATIONS OF EV MOTORS

\begin{tabular}{cc}
\hline EV models & EV motors \\
\hline Fiat Panda Elettra & DC motor \\
Mazda Bongo & DC motor \\
Conceptor G-Van & DC motor \\
Fiat Seicento Elettra & Induction motor \\
Ford Think City & Induction motor \\
GM EVI & Induction motor \\
Chloride Lucas & Switched reluctance motor \\
Honda EV Plus & PM brushless motor \\
Nissan Altra & PM brushless motor \\
Toyota RAV4 & PM brushless motor \\
Suzuki Senior Tricycle & PM brushless motor \\
\hline
\end{tabular}

TABLE II. EVALUATION OF EV Motors

\begin{tabular}{ccccccc}
\hline & $\begin{array}{c}\text { DC } \\
\text { motor }\end{array}$ & $\begin{array}{c}\text { Induction } \\
\text { motor }\end{array}$ & $\begin{array}{c}\text { PM brushless } \\
\text { motor }\end{array}$ & $\begin{array}{c}\text { SR } \\
\text { motor }\end{array}$ & $\begin{array}{c}\text { PM hybrid } \\
\text { motor }\end{array}$ \\
\hline Power density & 5 & 7 & 10 & 7 & 8 \\
Efficiency & 5 & 7 & 10 & 7 & 10 \\
Controllability & 10 & 7 & 8 & 7 & 8 \\
Reliability & 5 & 10 & 8 & 10 & 8 \\
Maturity & 10 & 10 & 8 & 8 & 6 \\
Cost & 8 & 10 & 6 & 7 & 5 \\
Total & 43 & 51 & 50 & 46 & 45 \\
\hline
\end{tabular}

\section{Structures of SPECial Electrical Machines in EVs}

In order to improve the density of power and torque of electrical machine, many novel special structures are investigated. This section will discuss the transverse flux machine (TFM), axial field machine (AFM), doubly salient permanent magnet machine (DSPM), and dual mechanical port electrical machine (DMPEM), as indicated in Fig. 3.

\section{A. Transverse Flux Machine (TFM)}

The TFM stator iron core has two basic structures: (1) That with U-shape poles which have both teeth in the same axial plane; and (2) That with claw-poles. For each phase, a toroidal winding is placed inside the stator teeth or poles. The rotor of TFM is shown in Fig. 3(a) [9].

The main advantages of TFM are its high torque density and high electric loading. It has a comparatively large number of poles, which are linked with the total ampere-conductors of each phase.

The main disadvantages of TFM are its large leakage flux, high winding inductance and poor power factor. Hence, the VA rating of the power electronics converter for this machine is relatively higher compared with that of conventional machine.
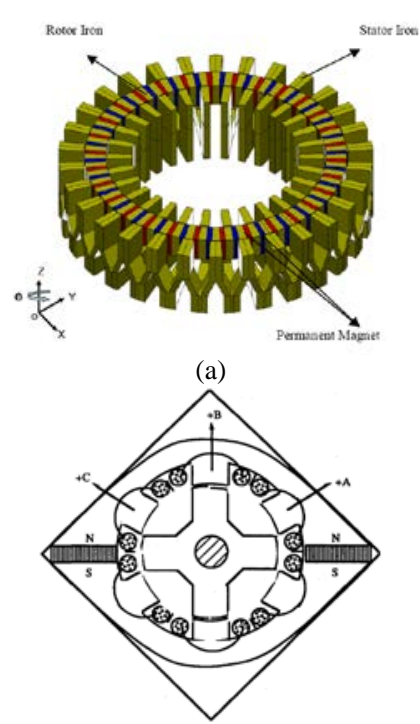

(c)

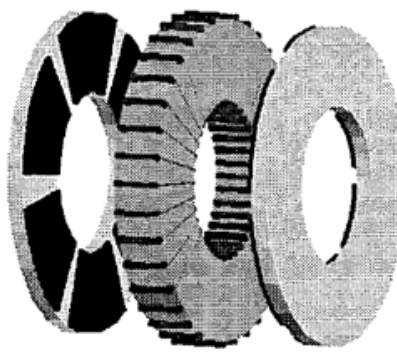

(b)

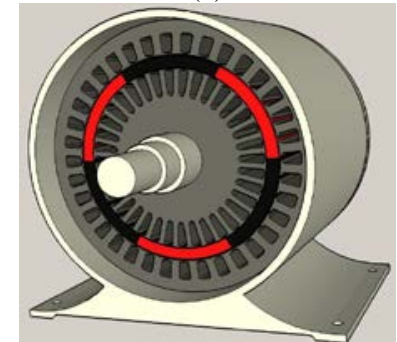

(d)
Figure 3. Structures of four special electrical machines: (a) TFM, (b) AFM, (c) DSPM, and (d) DMPEM.

\section{B. Axial Flux Machine (AFM)}

This machine has comparatively flexible dimensions, such as single-sided stator and a single rotor, double-sided stators and a single rotor, a single-sided stator and double-sided rotors which is indicated in Fig. 3(b). In each case, the air gap flux is in the axis direction [10].

The main advantages of AFM include high torque density and slotless stator. It has small cogging force.

The main disadvantages are relatively high manufacture cost. Furthermore, the winding inductance is small for large effective air gap, which limits the constant power speed range.

\section{Doubly Salient Permanent Magnet Machine (DSPM)}

A DSPM consists of switched reluctance machine and permanent magnet brushless DC machine. The cross section structure is indicated in Fig. 3(c) [11]. It is of three-phase, 6/4pole with stationary magnets, which is a simple pattern for motoring operation requiring satisfactory starting performance. The machine can take homo-polar, rotary magnet, and stationary magnet structures.

The DSPM is similar to that of the three-phase variable reluctance machine (VRM). The stator structure is the same as that of the VRM except that two pieces of PM are buried in the core and therefore introduced into the main flux path of the stator windings. High-performance PM material with a linear demagnetizing characteristic is used to sustain the magnetization and demagnetization of the armature reaction so as to keep a nearly constant flux level within the air gap [12].

The main advantages of DSPM include: (1) High torque density and high efficiency. (2) Simple, rugged structure and high speed capability. (3) Small VA rating of the power converter. (4) Low inertia and fast response. 
The main disadvantages are: (1) It is a pulsed-torque motor by nature, just like the VRM, which prevents the motor from applications where torque quality is critical. (2) Special consideration should be given to reduce the demagnetization effect of armature reaction in large machines. (3) Similar to other types of PM brushless machines, the regulation of air gap flux is difficult for field weakening control.

\section{Dual Mechanical Port Electrical Machine (DMPEM)}

The structure of DMPEM is shown in Fig.3 (d). It has two mechanical ports or mechanically rotating parts which are coupled by an energy conservative magnetic field. It has two rotors, viz. an outer PM rotor and an inner wound rotor. In $\mathrm{HEV}$, the DMPEM is mechanically coupled and electrically connected in the system [13].

The main advantages are: (1) Two ports of the DMPEM can input or output mechanical energy freely, and work in motor and generator modes at the same time. (2) The planetary gear set will not be used in the EVs propelled by the DMPEM. This machine with a single and compact package potentially achieves all functions and benefits that existing full EV technologies can achieve.

The main disadvantages include: (1) Magnetic field coupling exists between the inner and outer air-gaps, which affects the performances of the two mechanical ports greatly and brings much trouble in controlling. (2) The design and manufacture programs are more complicated than those of traditional machines.

\section{RESEARCh TRENDS OF ELECTRICAL MACHINES IN EVS}

Thanks to persistent hard work of both academic and industrial communities in the past years, the performance of electrical machines has been improved greatly. With quick development of industry technology, motor drive in EVs would meet with new renovations.

The research trends of the machine $R \& D$ in EVs are concluded below. (1) To develop high speed machines. By increasing speed, the size of electric motors may be reduced greatly, viz. higher power from smaller machines and redesigning for increased material utilization [1,3]. Some companies have started to focus on high speed of 16,000 rpm permanent magnet motors that can achieve field weakening within the structure of the motor and eliminate the need for a DC-DC boost converter [14]. (2) To develop system-level machine design scheme. It is necessary for the designers to take electrical machine, power electronics, such as converter, and fuel cell into consideration altogether [15]. Furthermore, control methods will be analyzed during the machine design so as to extend the constant power speed range (CPSR), increase the starting torque and etc. (3) To pay attention to PMBM. With quick development of new magnet materials, the cost and demagnetization drawbacks will be reduced. By employing new structures, such as auxiliary air gap in the stator, the fluxweakening ability of PMSM can be improved in the constant power area. (4) To develop electrical machines with composite structures. For traditional machines, each has its own merits and demerits. DSPM is a good example to combine SRM and PM motor for excellent performance. Hence, the traction machines consist of different structures may be noticed in the next step.

\section{CONCLUSIONS}

In this paper, the operational characteristics of traction machines in EVs are investigated. Four traditional machine structures (viz. DCM, IM, SRM, PMBM) and four special machine structures (viz. TFM, AFM, DSPM, DMPEM) have been reviewed, with emphasis on their advantages and disadvantages in terms of torque density, efficiency and cost. Performance comparisons among four traditional machines are provided, including speed-torque curve, power density, efficiency, controllability, reliability, maturity and etc. General speaking, all the four machine technologies can meet the performance requirements of traction drives, and each has its merits. With fast development of permanent materials, PMBM has been paid much attention, which has high efficiency and torque density. The issues on the trends of machine design in EVs are also described.

\section{REFERENCES}

[1] K. T. Chau, C. C. Chan, and L. Chunhua, "Overview of permanentmagnet brushless drives for electric and hybrid electric vehicles,” IEEE Trans. on Ind. Electron., vol. 55, no. 6, pp. 2246-2257, Jun. 2008.

[2] Z. Q. Zhu and D. Howe, "Electrical machines and drives for electric, hybrid, and fuel cell vehicles,” Proceedings of the IEEE, vol. 95, no. 4, pp. 746-765, Apr. 2007.

[3] A. Emadi, L. Young Joo, and K. Rajashekara, "Power electronics and motor drives in electric, hybrid electric, and plug-in hybrid electric vehicles,” IEEE Trans. Ind. Electron., vol. 55, no.6, pp. 2237-2245, Jun. 2008.

[4] D. W. Gao, C. Mi, and A. Emadi, "Modeling and simulation of electric and hybrid vehicles,” Proceedings of the IEEE, vol. 95, no. 4, pp. 729745, Apr. 2007.

[5] Allen Fuhs, Hybrid Vehicles and the Future of Personal Transportation. United States: CRC Press, 2008.

[6] M. Krishnamurthy, C. S. Edrington, A. Emadi, P. Asadi, M. Ehsani, and B. Fahimi, "Making the case for applications of switched reluctance motor technology in automotive products," IEEE Trans. Power Electron., vol. 21, no. 3, pp. 659-675, May 2006.

[7] J. Cros and P. Viarouge, "Synthesis of high performance PM motors with concentrated windings,” IEEE Trans. Energy Convers., vol. 17, no. 2, pp. 248-253, Jun. 2002.

[8] M. H. Rashid, Modern Electric, Hybrid Electric, and Fuel Cell Vehicles (Fundamentals, Theory, and Design), United States: CRC Press, 2005.

[9] N. Parspour, "Novel drive for use in electrical vehicles," in Vehicular Technology Conference, pp. 2930-2933, 2005.

[10] F. Marignetti, V. Delli Colli, and Y. Coia, "Design of axial flux PM synchronous machines through 3-D coupled electromagnetic thermal and fluid-dynamical finite-element analysis," IEEE Trans. Ind. Electron., vol. 55, no. 10, pp. 3591-3601, Oct. 2008.

[11] L. Yuefeng, L. Feng, and T. A. Lipo, “A novel permanent magnet motor with doubly salient structure,” IEEE Trans. Ind. Appl., vol. 31, no. 5, pp. 1069-1078, Sept./Nov. 1995.

[12] Y. B. Li, "Research on a novel stator doubly-fed doubly-salient permanent-magnet machine and its control system," Doctoral dissertation, Shanghai University, China, Jun. 2004.

[13] X. Longya, "A new breed of electric machines - basic analysis and applications of dual mechanical port electric machines,” in International Conference on Electrical Machines and Systems, pp. 24-31, 2005.

[14] Energy Efficiency and Renewable Energy Department, USA, "Plug-in hybrid electric vehicle R\&D plan,” Jun. 2007.

[15] C. C. Chan, "The state of the art of electric and hybrid vehicles," Proceedings of the IEEE, vol. 90, no. 2, pp. 247-275, Feb. 2002. 